\title{
Experimental study on interface friction between geosynthetic clay liner (GCL) and geomembrane under different hydration conditions
}

\author{
Xuan $\mathrm{Li}^{1,{ }^{*}}$,Yue Zhang ${ }^{2}$ \\ ${ }^{1}$ Hubei Business College, 430000 Wuhan, Hubei Province, China \\ ${ }^{2}$ Hubei Business College, 430000 Wuhan, Hubei Province, China
}

\begin{abstract}
The interfacial friction properties of GCL and geomembrane under different hydration conditions are discussed. In addition, the ionic solubility of hydration solution, the size of hydration normal stress and test conditions will affect the shear strength of GCL. In this paper, the friction properties of GCL upper geotextile and geomembrane interface are discussed from the following aspects: (1) hydration solutions with different ionic concentrations (deionized water, $0.05 \mathrm{~mol} / 1 \mathrm{CaCl}_{2}$ solution and $1: 1$ ethanol solution by volume); (2) different types of hydration solutions $\left(0.05 \mathrm{~mol} / 1 \mathrm{CaCl}_{2}\right.$ solution and $1: 1$ ethanol solution by volume); (3) different hydration normal stress conditions (pressureless hydration condition, $5 \mathrm{kPa}$ hydration condition and $10 \mathrm{kPa}$ hydration condition).
\end{abstract}

\section{Research background}

The shear failure of GCL generally occurs in the following three parts: inside the GCL; between the top surface and the overlying material; and between the bottom surface and the underlying material. ${ }^{[1]}$ Among them, the latter two belong to the interface shear strength failure, and the former is more damaged in practical engineering. The research structure shows that the internal failure of GCL caused by reinforcement will not affect the slope environment. However, when the bentonite in GCL interlayer is hydrated, the shear strength of the system will decrease rapidly. This will lead to the relative sliding between the surface layer and the bottom layer of GCL. ${ }^{[2]}$ If GCL is laid on the slope, not only the relative sliding between materials is easy to occur, but also the hidden sliding surface can easily appear due to the poor shear strength at this time. Considering that the bentonite in GCL may be extruded, the friction coefficient of other synthetic materials will also decrease. Therefore, the study on the interfacial shear strength between GCL and other geosynthetics has practical significance and engineering value for the application of GCL in landfill. ${ }^{[3]}$

\section{Preparation of test specimens}

The test materials include GCL, geomembrane and hydration solution.

In the process of the experiment, GCL and geomembrane are the experimental objects of interface friction. In terms of hydration solution, the composition of landfill leachate is complex, including a variety of organic matter, inorganic matter and toxic and harmful components. With the exchange of ions, the concentration of pollutants in the filtrate has a strong fluctuation, whether in a short time or in a long term, and the process is extremely complex. In addition, the composition of leachate is also affected by the location and distribution of the area, different components of garbage and different landfill methods, and its composition also shows different changes. ${ }^{[4]}$ Based on the laboratory test and the limitation of GCL material as sodium bentonite waterproof blanket, in order to analyse and compare the test results, the simulated leachate is deionized water, $0.05 \mathrm{~mol} / 1 \mathrm{CaCl}_{2}$ solution and ethanol solution (the volume ratio of ethanol to water is 1:1). The reasons are as follows: (1) Calcium ion and chloride ion are the main ions in landfill leachate. (2) When landfill leachate interacts with sodium bentonite waterproof blanket, the ion exchange mainly shows that calcium ion replaces sodium ion. (3) Deionized water is selected for the test to provide a comparative basis for the shear strength analysis of GCL under the action of solution. [5]

\section{Analysis of test results of interface friction between GCL and geomembrane under different hydration conditions}

\subsection{Analysis of test results of interface friction between hydrated GCL and geomembrane}

It can be seen from Fig. 1 that under the same normal stress, the interfacial shear stress between GCL and geomembrane under pressureless hydration condition is larger than that between GCL and geomembrane under

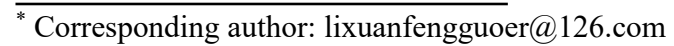


other conditions, the interfacial shear stress between GCL and geomembrane under $5 \mathrm{kpa}$ hydration condition is the second, and that between GCL and geomembrane under $10 \mathrm{kPa}$ hydration condition is the smallest. The interfacial shear stress of GCL is very close to that of geomembrane at $5 \mathrm{kPa}$ and $10 \mathrm{kPa}$. The interface peak strength of GCL and geomembrane under pressureless hydration state is the largest, followed by $5 \mathrm{kPa}$ normal stress hydration state, and the minimum interface peak strength of GCL and geomembrane under $10 \mathrm{kPa}$ normal stress hydration state. [6]

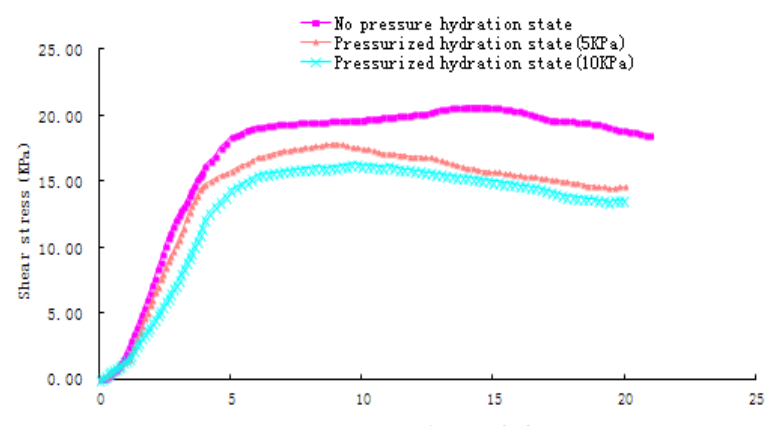

Shear di splacenent $(m)$

Fig. 1. Different hydration normal stress conditions of (pressureless hydration condition, $5 \mathrm{kPa}$ hdration condition and

$10 \mathrm{kPa}$ hydration condition) GCL and geomembrane graph

Table 1 shows that under the same normal stress, the peak value of interfacial shear stress of GCL under pressureless hydration condition is higher than that of GCL under $5 \mathrm{kPa}$ hydration condition and $10 \mathrm{kPa}$ hydration condition. The peak value of interfacial shear stress between GCL and geomembrane under pressureless hydration condition is $18.37 \%$ higher than that under $5 \mathrm{kPa}$ normal stress hydration condition and $8.05 \%$ higher than that under $10 \mathrm{kPa}$ normal stress hydration condition. It can be seen that the interfacial shear stress between GCL and geomembrane decreases with the increase of hydration normal stress.

Table 1. The improvement rate of GCL in different hydration conditions

\begin{tabular}{|c|c|c|c|c|}
\hline $\begin{array}{c}\text { Normal } \\
\text { stress }\end{array}$ & $50 \mathrm{kPa}$ & $100 \mathrm{kPa}$ & $150 \mathrm{kPa}$ & $200 \mathrm{kPa}$ \\
\hline $\begin{array}{c}\mathbf{5 k P a} \\
\text { Hydration } \\
\text { conditions }\end{array}$ & $25.57 \%$ & $25.40 \%$ & $18.37 \%$ & $25.44 \%$ \\
\hline $\begin{array}{c}\mathbf{1 0 k P a} \\
\text { Hydration } \\
\text { conditions }\end{array}$ & $11.29 \%$ & $13.19 \%$ & $8.05 \%$ & $16.64 \%$ \\
\hline
\end{tabular}

Under the condition of pressureless hydration, the cohesion between GCL and geomembrane is the largest, followed by $5 \mathrm{kPa}$ normal stress hydration, and the lowest under $10 \mathrm{kPa}$ normal stress hydration condition; while under the three conditions, the number of internal friction angles of GCL and geomembrane interface friction under pressureless hydration is the largest, and the internal friction angle under $5 \mathrm{kPa}$ normal stress hydration is several times, The number of internal friction angle is the smallest under the condition of $10 \mathrm{kPa}$ normal stress hydration. In comparison, the interface shear strength between GCL and geomembrane under pressureless hydration is the largest, followed by $5 \mathrm{kPa}$ normal stress hydration, and the minimum under $10 \mathrm{kPa}$ normal stress hydration.

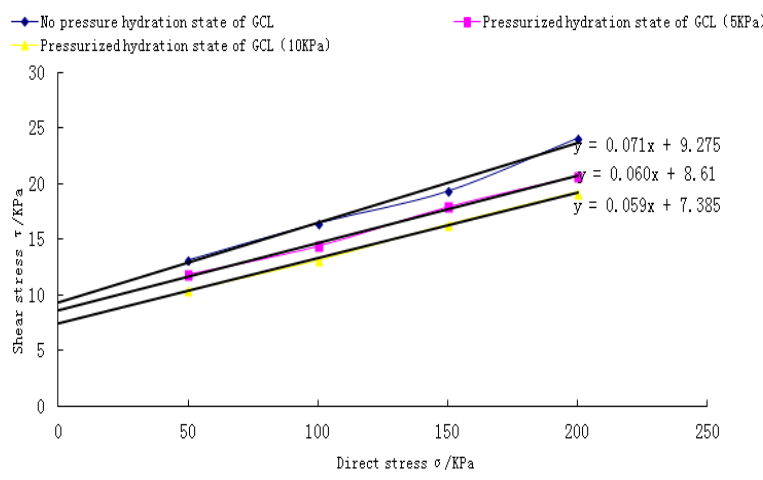

Fig. 2. GCL and geomembrane maximum shear stress and normal stress $\left(\tau_{f}-p\right)$ relationship graph

Table 2. Test results of interface friction between different hydration solutions GCL and geomembrane

\begin{tabular}{|c|c|c|c|}
\hline \multirow{1}{*}{$\begin{array}{c}\text { Geotechnical } \\
\text { materials }\end{array}$} & $\begin{array}{c}\text { Hydration } \\
\text { solution }\end{array}$ & Cohesion & $\begin{array}{c}\text { Friction } \\
\text { angle }\end{array}$ \\
\cline { 3 - 4 } & $\mathrm{c} / \mathrm{kPa}$ & $\varphi\left(^{\circ}\right)$ \\
\hline \multirow{2}{*}{$\begin{array}{c}\text { Go pressure } \\
\text { GeL and } \\
\text { geomembrane }\end{array}$} & $\begin{array}{c}\text { Hydration } \\
\text { conditions }\end{array}$ & 9.275 & $4.11^{\circ}$ \\
\cline { 2 - 4 } & $\begin{array}{c}\text { Hydration } \\
\text { conditions }\end{array}$ & 8.61 & $3.43^{\circ}$ \\
\cline { 2 - 4 } & $\begin{array}{c}10 \mathrm{kPa} \\
\text { Hydration } \\
\text { conditions }\end{array}$ & 7.385 & $3.38^{\circ}$ \\
\hline
\end{tabular}

\subsection{Analysis of GCL test results of $0.05 \mathrm{~mol} / \mathrm{l}$ $\mathrm{CaCl}_{2}$ solution hydration}

It can be seen from Figure 3 that under the same normal stress, the interface stress curve between GCL and geomembrane under pressureless hydration state is higher than that under other conditions, the interfacial shear stress value between GCL and geomembrane under $5 \mathrm{kPa}$ hydration condition is the second, and that between GCL and geomembrane under $10 \mathrm{kPa}$ hydration condition is the smallest. The interfacial shear stress of GCL is very close to that of geomembrane at $5 \mathrm{kPa}$ and 10KPA. The interface peak strength between GCL and geomembrane is $>5 \mathrm{kPa}$ normal stress hydration state $>10 \mathrm{kPa}$ normal stress hydration state under pressureless hydration state.

It is shown in Table 3 that under the same normal stress, the peak value of interfacial shear stress under pressureless hydration condition of GCL is higher than that of GCL under $5 \mathrm{kPa}$ hydration condition and $10 \mathrm{kPa}$ hydration condition. The peak value of interfacial shear stress between GCL and geomembrane under pressureless hydration is $0.84 \%$ higher than that under $\quad 5 \mathrm{kPa}$ normal stress hydration condition, and $14.96 \%$ higher than that under $10 \mathrm{kPa}$ normal stress hydration condition. It can be seen that the interfacial shear stress between GCL and geomembrane after hydration with $0.05 \mathrm{~mol} / 1 \quad \mathrm{CaCl}_{2}$ solution decreases with the increase of hydration normal stress. 


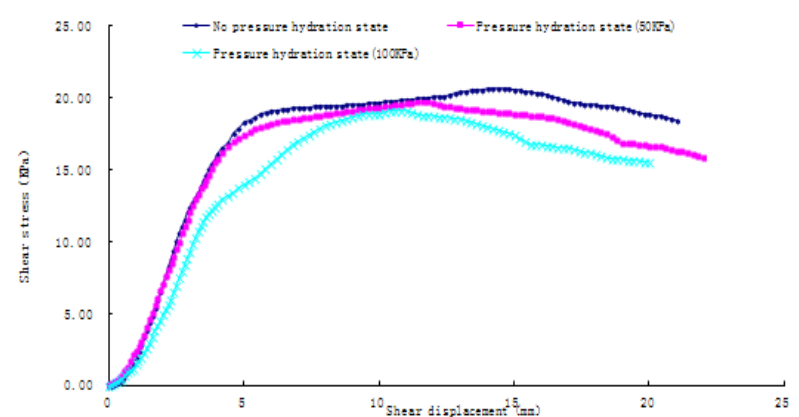

Fig. 3. Different hydration normal stress conditions of (pressureless hydration condition, $5 \mathrm{kPa}$ hydration condition and $10 \mathrm{kPa}$ hydration condition) GCL and geomembrane graph

Table 3. The improvement rate of GCL in different hydration conditions

\begin{tabular}{|c|c|c|c|c|}
\hline $\begin{array}{c}\text { Normal } \\
\text { stress }\end{array}$ & $50 \mathrm{kPa}$ & $100 \mathrm{kPa}$ & $150 \mathrm{kPa}$ & $200 \mathrm{kPa}$ \\
\hline $\begin{array}{c}\mathbf{5 k P a} \\
\text { Hydration } \\
\text { conditions }\end{array}$ & $0.84 \%$ & $6.21 \%$ & $2.93 \%$ & $4.22 \%$ \\
\hline $\begin{array}{c}\mathbf{1 0 k P a} \\
\text { Hydration } \\
\text { conditions }\end{array}$ & $20.18 \%$ & $26.18 \%$ & $14.96 \%$ & $19.35 \%$ \\
\hline
\end{tabular}

Under the condition of pressureless hydration, the cohesion between GCL and geomembrane is the largest, followed by $5 \mathrm{kPa}$ normal stress hydration, and the lowest under $10 \mathrm{kPa}$ normal stress hydration; and under the three conditions, the number of internal friction angles of GCL and geomembrane under the condition of pressureless hydration is the largest, the internal friction angle of $5 \mathrm{kPa}$ normal stress hydration is several times, and that of $10 \mathrm{kPa}$ normal stress hydration is the highest The number of internal friction angles is the smallest. In comparison, the interface shear strength between GCL and geomembrane under pressureless hydration is the largest, followed by $5 \mathrm{kPa}$ normal stress hydration, and the minimum under $10 \mathrm{kPa}$ normal stress hydration.

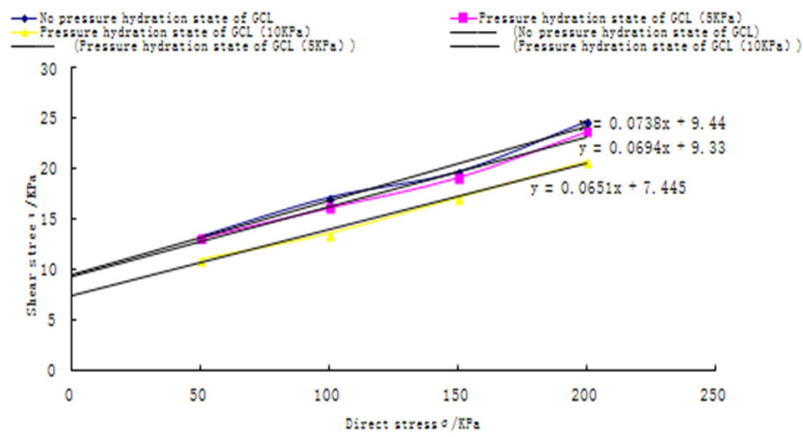

Fig. 4. GCL and geomembrane maximum shear stress and normal stress $\left(\tau_{f}-p\right)$ relationship graph

Table 4. Test results of interface friction between different hydration solutions GCL and geomembrane

\begin{tabular}{|c|c|c|c|}
\hline $\begin{array}{c}\text { Geotechnical } \\
\text { materials }\end{array}$ & $\begin{array}{c}\text { Hydration } \\
\text { solution }\end{array}$ & Cohesion & $\begin{array}{c}\text { Friction } \\
\text { angle }\end{array}$ \\
\hline
\end{tabular}

\begin{tabular}{|c|c|c|c|}
\hline & & $\mathrm{c} / \mathrm{kPa}$ & $\varphi\left({ }^{\circ}\right)$ \\
\hline \multirow{3}{*}{$\begin{array}{c}\text { GCL and } \\
\text { geomembrane }\end{array}$} & $\begin{array}{l}\text { No pressure } \\
\text { Hydration } \\
\text { conditions }\end{array}$ & 9.44 & $4.18^{\circ}$ \\
\hline & $\begin{array}{c}5 \mathrm{kPa} \\
\text { Hydration } \\
\text { conditions }\end{array}$ & 9.33 & $3.94^{\circ}$ \\
\hline & $\begin{array}{c}10 \mathrm{kPa} \\
\text { Hydration } \\
\text { conditions }\end{array}$ & 7.445 & $3.72^{\circ}$ \\
\hline
\end{tabular}

\subsection{Analysis of hydration test results of ethanol (volume ratio 1:1)}

It can be seen from Fig. 5 that under the same normal stress, the interface shear stress curve between GCL and geomembrane under pressureless hydration state and between GCL and geomembrane under $5 \mathrm{kPa}$ hydration condition are higher than that between GCL and geomembrane under $10 \mathrm{kPa}$ hydration condition. The interfacial shear stress curves of GCL and geomembrane under pressureless hydration state and GCL with geomembrane under $5 \mathrm{kPa}$ hydration condition are intertwined together, without obvious regularity. However, it can be seen from the figure that the interface peak strength between GCL and geomembrane is the largest under $5 \mathrm{kPa}$ hydration condition, followed by GCL and geomembrane under pressureless hydration condition, and the minimum interface peak strength between GCL and geomembrane under $10 \mathrm{kPa}$ normal stress.

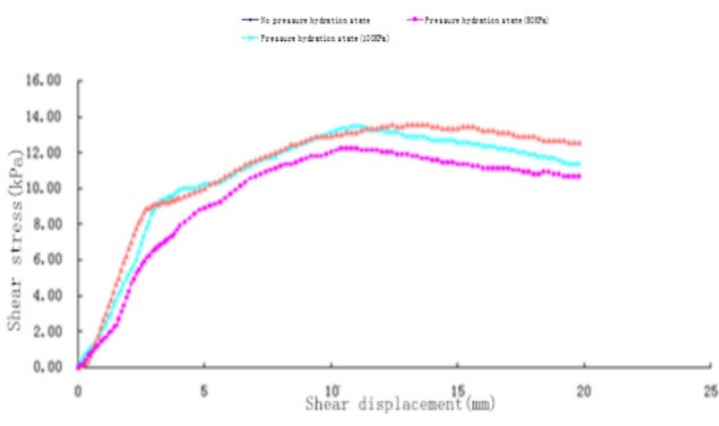

Fig. 5. Different hydration normal stress conditions of (pressureless hydration condition, $5 \mathrm{kPa}$ hydration condition and $10 \mathrm{kPa}$ hydration condition) GCL and geomembrane graph

It is shown in Table 5 that under the same normal stress, the peak value of interfacial shear stress under pressureless hydration condition of GCL is higher than that of GCL under $5 \mathrm{kPa}$ hydration condition and $10 \mathrm{kPa}$ hydration condition. The peak shear stress ratio of GCL to clay under pressureless hydration condition is $3.24 \%$ less than that under $5 \mathrm{kPa}$ normal stress hydration condition, and is at least $8.04 \%$ higher than that under $10 \mathrm{kPa}$ normal stress hydration condition. It can be seen that the interfacial shear stress between GCL and clay decreases with the increase of hydration normal stress. 
Table 5. The improvement rate of GCL in different hydration conditions

\begin{tabular}{|c|c|c|c|c|}
\hline $\begin{array}{c}\text { Normal } \\
\text { stress }\end{array}$ & $50 \mathrm{kPa}$ & $100 \mathrm{kPa}$ & $150 \mathrm{kPa}$ & $200 \mathrm{kPa}$ \\
\hline $\begin{array}{c}\mathbf{5 k P a} \\
\text { Hydration } \\
\text { conditions }\end{array}$ & $-3.24 \%$ & $10.90 \%$ & $10.22 \%$ & $0.45 \%$ \\
\hline $\begin{array}{c}\mathbf{1 0 k P a} \\
\text { Hydration } \\
\text { conditions }\end{array}$ & $8.04 \%$ & $8.04 \%$ & $19.78 \%$ & $10.04 \%$ \\
\hline
\end{tabular}

Under the condition of pressureless hydration, the cohesion between GCL and geomembrane is the largest followed by $5 \mathrm{kPa}$ normal stress hydration and $10 \mathrm{kPa}$ normal stress hydration. Under the three conditions, the number of internal friction angles of GCL and geomembrane interface under pressureless hydration is the largest, the internal friction angle under $5 \mathrm{kPa}$ normal stress hydration is several times, and the internal friction angle number under $10 \mathrm{kPa}$ normal stress hydration condition is the minimum. In comparison, the interface shear strength between GCL and geomembrane under pressureless hydration is the largest, followed by $5 \mathrm{kPa}$ normal stress hydration, and the minimum under $10 \mathrm{kPa}$ normal stress hydration.

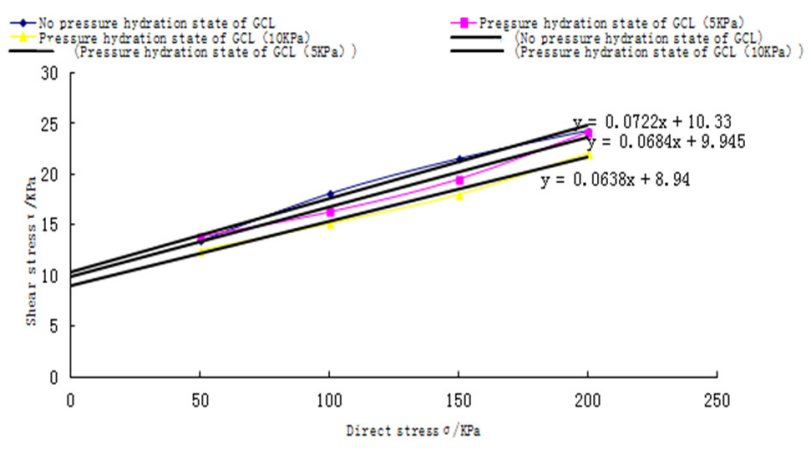

Fig. 6. GCL and geomembrane maximum shear stress and normal stress $\left(\tau_{f}-p\right)$ relationship graph

Table 6. Test results of interface friction between different hydration solutions GCL and geomembrane

\begin{tabular}{|c|c|c|c|}
\hline \multirow{2}{*}{$\begin{array}{c}\text { Geotechnical } \\
\text { materials }\end{array}$} & $\begin{array}{c}\text { Hydration } \\
\text { solution }\end{array}$ & Cohesion & $\begin{array}{c}\text { Friction } \\
\text { angle }\end{array}$ \\
\cline { 3 - 4 } & $\mathrm{c} / \mathrm{kPa}$ & $\varphi\left({ }^{\circ}\right)$ \\
\hline \multirow{2}{*}{$\begin{array}{c}\text { No pressure } \\
\text { Geomembrand } \\
\text { gydration } \\
\text { conditions }\end{array}$} & $\begin{array}{c}5 \mathrm{kPa} \\
\text { Hydration } \\
\text { conditions }\end{array}$ & 9.954 & $3.89^{\circ}$ \\
\cline { 2 - 4 } & $\begin{array}{c}10 \mathrm{kPa} \\
\text { Hydration } \\
\text { conditions }\end{array}$ & 8.94 & $3.60^{\circ}$ \\
\hline
\end{tabular}

\section{Summary}

The conclusions obtained through the above-mentioned experimental analysis are as follows:
1. the shear strength of GCL and clay is the largest under pressureless hydration condition; the interfacial shear stress between GCL and geomembrane decreases with the increase of hydration normal stress after deionized hydration, and the maximum shear strength of GCL and geomembrane under pressureless hydration is $5 \mathrm{kPa}$ the shear strength under normal stress hydration is the second, and the shear strength under $10 \mathrm{kPa}$ normal stress hydration is the lowest.

2. The interface shear strength between GCL and geomembrane is the largest under pressureless hydration, followed by $5 \mathrm{kPa}$ normal stress hydration, and the lowest under $10 \mathrm{kPa}$ normal stress hydration.

3. the shear strength of GCL and geomembrane under pressureless hydration is the largest, followed by $5 \mathrm{kPa}$ normal stress hydration, and the lowest under $10 \mathrm{kPa}$ normal stress hydration.

4. Under the condition of pressureless hydration, $5 \mathrm{kpa}$ normal stress hydration and $10 \mathrm{kPa}$ normal stress hydration, the shear resistance of interface friction between GCL and geomembrane is ethanol $>0.05 \mathrm{~mol} / 1 \mathrm{CaCl}_{2}$ solution $>$ deionized water.

\section{References}

1. X. Li, Laboratory investigation on the interface of GCL and Geomembrane. (2013)

2. C. Xu, H. Xing. Geosynthetics. (2010)

3. L. Yu. Analysis of interface friction characteristics between geosynthetics and sand. (2012)

4. X. Kong, Experimental study on the anti-seepage performance of GCL in liner of waste landfill. (2011)

5. J.Zhou, Environmental Geotechnical Engineering. (2009)

6. X. Li, Y. Zhang. Study on the effect of hydration on the shear strength of the interface between geosynthetic clay liner (GCL) and geomembrane. (2020) 